\title{
Differential resistance to extended copper exposure in four introduced bryozoans
}

\author{
Richard F. Piola*, Emma L. Johnston \\ School of Biological, Earth and Environmental Sciences, University of New South Wales, Sydney, New South Wales 2052, \\ Australia
}

\begin{abstract}
Resistance to copper by some fouling species may have the 2 -fold effect of both facilitating the introduction of nonindigenous species via the painted hulls of vessels, and providing these species with a competitive advantage in ports or estuaries already exposed to anthropogenically elevated copper concentrations. This study tested the tolerance of 4 introduced bryozoans, Bugula neritina, Watersipora subtorquata, Schizoporella errata and Tricellaria occidentalis, to a range of Cu concentrations $(0$, $10,50,100$ and $500 \mathrm{\mu g} \mathrm{l}^{-1}$ ). Larval attachment after $24 \mathrm{~h}$ was not found to be a reliable indicator of postmetamorphic survival. Recruits of all species survived in 0 and $10 \mu \mathrm{g} \mathrm{l}^{-1} \mathrm{Cu}$ for $20 \mathrm{~d}$, with only Bugula neritina and Watersipora subtorquata recruits surviving exposure to 50 and $100 \mu \mathrm{g} \mathrm{l}^{-1} \mathrm{Cu}$. B. neritina and $W$. subtorquata colonies exhibited reduced post-metamorphic growth in $50 \mu \mathrm{g} \mathrm{l}^{-1} \mathrm{Cu}$ compared to controls, with no growth observed in $100 \mu \mathrm{g} \mathrm{l^{-1 }} \mathrm{Cu}$. Growth for S. errata and T. occidentalis was higher at $0 \mu \mathrm{g} \mathrm{l}^{-1}$ than $10 \mu \mathrm{g} \mathrm{l}^{-1} \mathrm{Cu}$. Post-exposure growth of surviving colonies was assessed by transplanting colonies to the field. $W$. subtorquata colonies exposed to $50 \mu \mathrm{g} \mathrm{l^{-1 }} \mathrm{Cu}$ were the only colonies to show decreased survival and growth post Cu-exposure. Overall, B. neritina and W. subtorquata showed the greatest tolerance to $\mathrm{Cu}$. These findings have important implications for the management, control and assessment of invasion potential of these invasive marine hull-fouling species.
\end{abstract}

KEY WORDS: $\mathrm{Cu} \cdot$ Attachment $\cdot$ Post-metamorphic survival $\cdot$ Post-metamorphic growth $\cdot$ Antifouling paint $\cdot$ Tolerance $\cdot$ Introduced species $\cdot$ Hull fouling

\section{INTRODUCTION}

In many ecosystems the distribution and abundance of organisms is strongly affected by human disturbances. Two of the greatest threats to marine biodiversity and system health worldwide are the spread (or invasion) of introduced marine species (Carlton \& Geller 1993, Holloway \& Keough 2002, Hayes et al. 2004) and exposure to anthropogenic pollution (Rygg 1985a, Rygg 1985b, Luoma \& Phillips 1988, Cohen \& Carlton 1998, Preston \& Shackelford 2002).

Sessile marine invertebrates in bays and estuaries are among the most vulnerable marine communities to invasion, due to both an abundant supply of invasive propagules (or larvae) through a wide range of transport vectors (Carlton \& Geller 1993), and the high levels of anthropogenic disturbance that occur in these locations (Cohen \& Carlton 1998). Anthropogenic dis- turbances can act to weaken and alter the structure of marine invertebrate communities, allowing introduced species to gain a foot-hold and potentially spread (Clark \& Johnston 2005).

Copper is a common toxicant in the marine environment that has the potential to affect both the spread of nonindigenous species and the health of epifaunal assemblages in bays and estuaries. Many ports and harbours are exposed to copper pollution via anthropogenic discharge into estuaries, embayments and streams in the form of industrial waste (Apte \& Day 1998, Hall Jr. et al. 1998), urban runoff and sewage discharge (Scanes 1996, Pitt 2002), wood preservatives (Weis \& Weis 1992, 1996) and from boat hulls via antifouling biocides (Paulson et al. 1989). While copper is a trace element found naturally at low concentrations in the aquatic environment, at higher concentrations it is considered one of the 3 most toxic heavy metals to 
marine invertebrates of several trophic groups (Hall et al. 1998). Copper has been shown to decrease the reproductive success, growth rates and abundance of many species (Hall et al. 1998), and lead to changes in the structural composition of benthic communities (Weis \& Weis 1992, Johnston et al. 2002).

In recent years, hull fouling of ships and recreational vessels has been identified as an important vector for the transport and spread of nonindigenous species (Minchin \& Gollasch 2003, Floerl et al. 2004, Hewitt et al. 2004). The frequency of nonindigenous species transport may increase as tributyl tin (TBT), the primary antifouling biocide used on most large commercial vessels worldwide, is phased out by 2008 (I.M.O. 2001), and replaced by alternative less effective biocides such as copper. Floerl et al. (2004) found that despite the use of copper-based antifouling paints on boat hulls, several recognized nonindigenous species were able to colonise the primary and/or secondary surfaces of some vessel hulls.

Thus the possibility exists that resistance to copper by some fouling species may have the 2-fold effect of both facilitating the introduction of nonindigenous species via the hulls of vessels, and providing these species with a competitive advantage in ports or estuaries already exposed to anthropogenically elevated copper concentrations.

As such there exists a need to quantify the extent to which known nonindigenous ship hull fouling species are able to establish and grow in the presence of a copper toxicant. While many studies exist on the toxicity of copper to invertebrate species, they are generally concerned with determining LC50's or dose-response relationships in the laboratory (Abel 1989, Callow 1994). Larvae are generally recognised as the invertebrate life-stage most sensitive to toxicants (Connor 1972, Calabrese et al. 1973, McKim 1977) and as a result studies into the effect of toxicants on invertebrates often end shortly after larval metamorphosis. The duration of such studies is generally $<96 \mathrm{~h}$, with little concern for the effects of prolonged exposure (several weeks) or the recovery success of organisms once exposure has ceased (but for exceptions see $\mathrm{Ng} \&$ Keough 2003). While this approach is beneficial for testing the short-term events such as attachment or settlement, it may be of limited use to the overall management of nonindigenous species, since the survival and growth of only a few individuals from a population may be sufficient for a successful invasion to occur.

The aims of this study were to investigate and compare the toxicity of copper to 4 cosmopolitan bryozoan species, Bugula neritina, Watersipora subtorquata, Schizoporella errata and Tricellaria occidentalis. Bryozoans form an abundant component of most epibenthic communities (Gordon \& Mawatari 1992), and are common fouling organisms on the hulls of ocean-going vessels (Gordon \& Mawatari 1992, Minchin \& Gollasch 2003, Floerl et al. 2004). All 4 bryozoans species in this study are recognised as national priority pest species within Australian waters, with invasion potentials ranging from medium to high (Hayes et al. 2004). Studies have already demonstrated that $B$. neritina and $W$. subtorquata have the ability to grow on (Floerl et al. 2004) and around (Johnston \& Webb 2000) surfaces treated with copper-based antifouling paints, however little research exists on the settlement, survival and growth success of $S$. errata and $T$. occidentalis in the presence of copper. The specific aims will be to: (1) determine the attachment success of bryozoan larvae and (2) the post-metamorphic survival and growth of colonies exposed to a range of copper concentrations over $20 \mathrm{~d}$, and (3) assess the post-exposure survival and growth of field-transplanted colonies (up to $4 \mathrm{wk}$ ).

This study sets a benchmark by which to compare the tolerance of endemic species to copper so that we may better understand the role of toxicants in facilitating the introduction of nonindigenous species into native assemblages.

\section{MATERIALS AND METHODS}

Sample collection. Adult colonies of Bugula neritina, Watersipora subtorquata and Tricellaria occidentalis were collected from Caltex Pier, Kurnell, in Botany Bay, NSW Australia. Colonies of Schizoporella errata were collected from Rose Bay, in Port Jackson, NSW Australia. Colonies were transported and stored in aerated tanks of filtered seawater collected from their respective field sites. They were maintained in darkness for $2 \mathrm{~d}$ before being induced to spawn through exposure to bright light (Wisely 1958).

Copper treatments. In all experiments, analytical grade copper II chloride hydrous $\left(\mathrm{CuCl}_{2} \cdot 2 \mathrm{H}_{2} \mathrm{O}\right)$ was used as the reference toxicant. A $1000 \mathrm{mg} \mathrm{l}^{-1} \mathrm{Cu}$ stock solution was prepared by dissolving $1.34 \mathrm{~g}$ of $\mathrm{CuCl}_{2} \cdot 2 \mathrm{H}_{2} \mathrm{O}$ in $500 \mathrm{ml}$ of Milli-Q ${ }^{\circledR}$ filtered water. Stock solution was stored at $4^{\circ} \mathrm{C}$ to prevent reduction of $\mathrm{Cu}$ ions in solution. A $1000 \mu \mathrm{g} \mathrm{l}^{-1} \mathrm{Cu}$ solution was prepared from this stock solution each day and diluted in order to obtain all experimental treatment solutions of 10,50, 100 and $500 \mu \mathrm{g} \mathrm{l}^{-1} \mathrm{Cu}$. Filtered seawater collected from the field sites was used as the dilution medium. Seawater was filtered through a $0.2 \mu \mathrm{m}$ filter to reduce the possibility of complexation of $\mathrm{Cu}$ with organic particles and maximise the amount of biologically available $\mathrm{Cu}$ in solution (Campbell 1995, Batley et al. 2004). All equipment was acid washed in $5 \%$ nitric acid for a minimum of $24 \mathrm{~h}$ and rinsed in Milli- $\mathrm{Q}^{\circledR}$ filtered water prior to use. 
In preparation for analysis, $60 \mathrm{ml}$ sub-samples of $\mathrm{Cu}$ treatment solutions were collected at the commencement of the experiments and immediately acidified with analytical grade nitric acid ( $1.5 \mu \mathrm{l}$ of acid per $1 \mathrm{ml}$ of sample) and refrigerated. The actual concentration of copper in stock and experimental solutions was then independently tested by the Australian Government National Measurement Institute (detection limit of $5 \mathrm{\mu g} \mathrm{l}^{-1}$ ).

20 d toxicity tests. The attachment success and postmetamorphic survival and growth of bryozoan larvae and recruits exposed to copper were determined during 20 d laboratory toxicity experiments conducted in April and May 2004. Plastic Petri dishes (35 mm in diameter) were used as the experimental containers. Each dish was acid washed then pre-soaked in the appropriate copper solution for $24 \mathrm{~h}$ prior to commencing the experiments to ensure minimal chelation (or binding) of any bioavailable $\mathrm{Cu}$ in solution during the exposure period. Pilot studies indicated that larvae of some bryozoan species in this experiment develop to fully feeding settled individuals between 1 and $2 \mathrm{~d}$ after attachment and metamorphosis. Therefore, from Day 2 onwards a food source (the microalgae Isochrysis galbana) was included as a component of each treatment solution at a concentration of $10^{5}$ cells $\mathrm{ml}^{-1}$. Algal sorption has the potential to reduce the bioavailability of $\mathrm{Cu}$ by up to $20 \%$ in solutions with high $\mathrm{Cu}$ concentrations (e.g. 50, 100 and $500 \mathrm{\mu g} \mathrm{l}^{-1}$ ) and up to $45 \%$ in solutions of low $\mathrm{Cu}$ concentration (e.g. $10 \mu \mathrm{g} \mathrm{l}^{-1}$ ) (as shown in Xie et al. 2005). Due to this, nominal copper concentrations in this study are effectively range values, with the concentrations used in each experiment being $0,5-10,40-50,80-100$ and 400-500 $\mathrm{gg} \mathrm{l}^{-1} \mathrm{Cu}$, with 6 replicate dishes for each treatment. For ease of presentation of results however, these nominal concentration ranges will continue to be referred to as $0,10,50,100$ and $500 \mu g ~^{-1} \mathrm{Cu}$. Concentrations ranges of $5-10$ and $40-50 \mu \mathrm{g} \mathrm{l}^{-1} \mathrm{Cu}$ represent relevant values that do exist in polluted aquatic environments (Stauber et al. 2000, Schiff et al. 2004), while

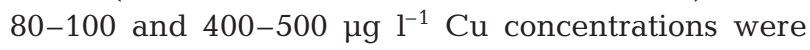
primarily included to gauge maximum tolerance limits. Exposure to treatments was maintained for $20 \mathrm{~d}$. Solutions were replaced daily with solutions prepared from stock solution immediately prior to use.

In order to reduce the size of the experiment, treatment dishes were inoculated with the larvae of 2 bryozoan species. One series of treatment dishes was inoculated with larvae of Bugula neritina and Schizoporella errata, while a second treatment series was inoculated with Watersipora subtorquata and Tricellaria occidentalis larvae. The total volume of treatment solution in each dish was $4.5 \mathrm{ml}$. At no time during the experiments did the organism loading come close to exceeding the specified ATSM 1192-97 guidelines of 0.5 to $0.8 \mathrm{~g}$ organism $\mathrm{l}^{-1}$ (ASTM 1999), nor was any intra-specific interaction between larvae observed. The number of larvae of each species put into each Petri dish was dependant on the individual spawning success of adult colonies, with 20 larvae of B. neritina, 10 larvae of $W$. subtorquata and T. occidentalis and 5 . errata larvae being added to each container. Following inoculation of larvae, all treatments were kept in darkness for $24 \mathrm{~h}$ to encourage settlement, after which time they were subjected to a shaded 12:12 light:dark cycle. All experiments were conducted at a constant temperature of $20^{\circ} \mathrm{C}$.

After $24 \mathrm{~h}$ the number of attached larvae was recorded in each container using a dissecting microscope. Attachment was defined as a larva that had attached to the surface of the container and initiated metamorphosis into the ancestrula. The location of individual larvae within the container was mapped for reference. The subsequent survival and growth of settled larvae was recorded at 5, 10, 15 and 20 d. Survival was defined as successful metamorphosis resulting in a zooid with a primary orifice present. A zooid was deemed to be dead if it appeared empty or if only a brown-body (Brusca \& Brusca 1990) was visible. Growth was recorded by counting the number of new zooids budded from each ancestrula, with a bud being counted as a new zooid once a primary orifice had developed.

Laboratory-to-field transfer. To assess the recovery ability and possible carry-over effects of copper exposure on the survival and growth of bryozoan colonies all Petri dishes were transferred into the field immediately after completion of the laboratory exposure period $(20 \mathrm{~d})$. The laboratory-to-field transfers were conducted between May and June. The field site was located at Caltex Pier, at Kurnell in Botany Bay, NSW Australia, $15 \mathrm{~km}$ south of Sydney. The pier extends $1.3 \mathrm{~km}$ from the southern shore of the bay, and experiments were deployed approximately $500 \mathrm{~m}$ from the shore. Naturally occurring sessile assemblages of sponges, ascidians, bryozoans, polychaetes, hydrozoans, anthozoans and macroalgae have been previously documented at Caltex Pier (Pollard \& Pethebridge 2002). The background concentrations of total copper in the water at the pier are less than $5 \mu \mathrm{g} \mathrm{l}^{-1}$ (R. F. Piola \& E. L. Johnston unpubl. data).

Petri dishes were randomly arranged onto a PVC backing plate $(50 \times 50 \times 0.5 \mathrm{~cm})$ and attached using silicon glue. The backing plate was suspended in the water column at a depth of $2 \mathrm{~m}$ below low water mark with treatment dishes on the underside to minimise available light and sedimentation. A counter-weight was attached below the backing plate to provide stability. Dishes were retrieved from the field after $26 \mathrm{~d}$ and transported back to the laboratory and maintained in a recirculating seawater system prior to census. 

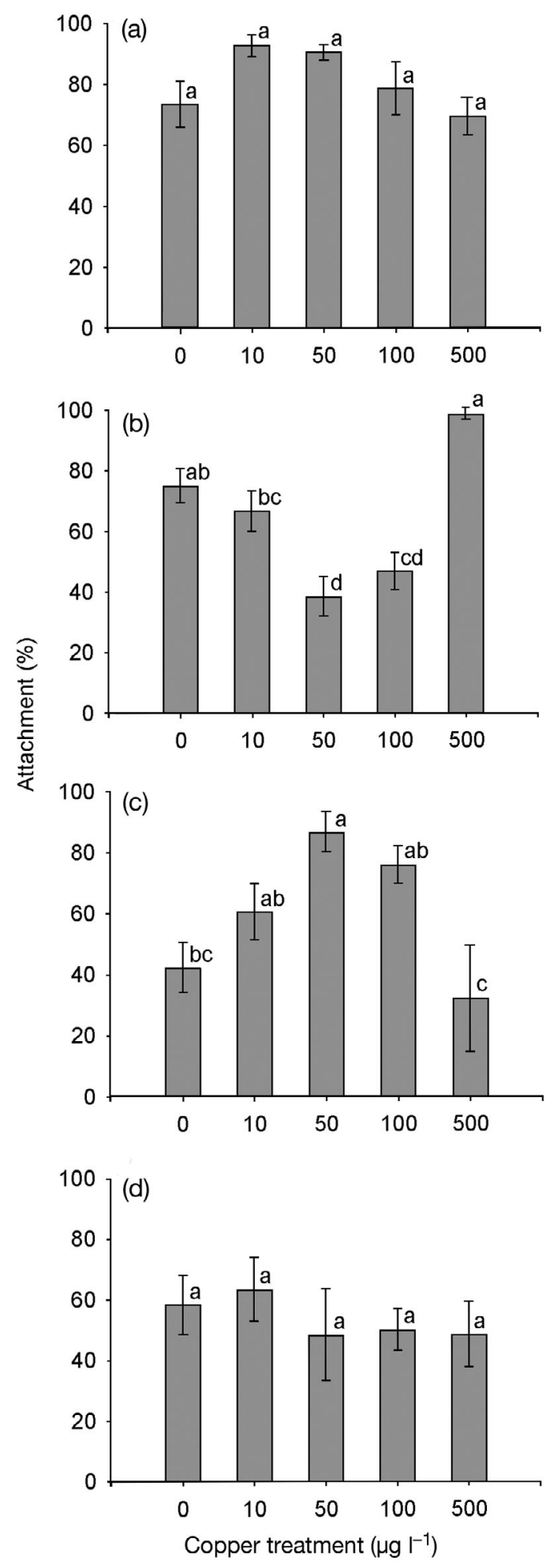

Fig. 1. Effects of $0,10,50,100$ and $500 \mathrm{\mu g} \mathrm{l}^{-1} \mathrm{Cu}$ treatment on the attachment of (a) Bugula neritina, (b) Watersipora subtorquata, (c) Schizoporella errata and (d) Tricellaria occidentalis recruits after $24 \mathrm{~h}$ exposure. Bars represent mean $( \pm 1 \mathrm{SE})$. Different letters represent significant differences in Tukey's post-hoc comparisons $(\alpha=0.05)$
During counting, colonies derived from experimental larvae were distinguished from colonies growing from field recruitment using the mapped positions recorded during the laboratory experiments. The number of colonies surviving in each dish was counted and recorded as a percentage of the colonies present in the dish at the time of field deployment. Due to the differing growth morphologies among the species (Bugula neritina and Tricellaria occidentalis are arborescent bryozoans while Watersipora subtorquata and Schizoporella errata are encrusting), 2 different techniques for estimating growth were employed. For the arborescent species, growth was assessed by counting the number of bifurcations along 3 separate branch lengths within any one colony. This number was then averaged to get a mean value for that colony. Bifurcations have been found to be a reliable estimate of colony size (Keough \& Chernoff 1987). For the encrusting species, the total number of zooids in each colony was counted with the aid of image analysis software.

Data analysis. Differences in the percent attachment of larvae of each species were analysed using a 1-factor ANOVA with copper treatment as a fixed factor. Tukey's post-hoc tests were conducted on significant results to test for differences between copper treatments. Repeated measures analysis of variance was used to test for the effects of copper on the percent survival and growth of larvae during the $20 \mathrm{~d}$ laboratory exposure, with $\mathrm{Cu}$ treatment being the betweensubjects effect and time the repeated effect. Planned comparisons were carried out on significant results to determine differences between specific $\mathrm{Cu}$ treatments, with all planned comparisons tested against the error term for the main test of copper treatment (Quinn \& Keough 2002). For the laboratory-to-field transfer a 1factor ANOVA was used to test for variation in the post-metamorphic survival and growth of recruits with $\mathrm{Cu}$ treatment as a fixed factor. Tukey's post-hoc tests were performed on significant results to test for differences between $\mathrm{Cu}$ treatments. All data was assessed for homogeneity of variance and normality using plots of residuals versus means and descriptive statistics; and when required analysis was performed on squareroot transformed data.

\section{RESULTS}

\section{Larval attachment}

The proportion of larvae attaching to Petri dishes after $24 \mathrm{~h}$ across all $\mathrm{Cu}$ treatments and species ranged between 38 and $98 \%$ attachment (Fig. 1). There was no significant difference in the attachment rate of Bugula neritina $\left(F_{4,25}=2.755, \mathrm{p}=0.050\right.$; Fig. 1a) or Tricellaria 
occidentalis $\left(F_{4,25}=0.382, \mathrm{p}=0.819\right.$; Fig. 1d) larvae across $\mathrm{Cu}$ treatments, though $T$. occidentalis showed decreased attachment overall (48 to $63 \%$ ) compared with B. neritina (73 to $93 \%$; Fig. 1a,d). Attachment of Watersipora subtorquata larvae varied between treatments $\left(F_{4,25}=17.726, \mathrm{p}<0.001\right.$; Fig. $\left.1 \mathrm{~b}\right)$ with reduced recruitment at 50 and $100 \mathrm{\mu g} \mathrm{l}^{-1} \mathrm{Cu}$ compared to the control and $10 \mu \mathrm{g} \mathrm{l}^{-1} \mathrm{Cu}$ treatments (Fig. 1b). Interestingly there was almost $98 \%$ attachment occurring at the highest $\mathrm{Cu}$ concentration of $500 \mathrm{\mu g} \mathrm{l}^{-1}$ (Fig. 1b). Significant differences occurred in Schizoporella errata attachment between treatments $\left(F_{4,24}=6.501, \mathrm{p}=0.001\right.$; Fig. 1c), with attachment of larvae increasing from $42 \%$ in the control treatment, up to a peak of 87 and $76 \%$ in 50 and $100 \mu \mathrm{g} \mathrm{l}^{-1} \mathrm{Cu}$ treatments, followed by a minimum of $32 \%$ at $500 \mu \mathrm{g} \mathrm{l}^{-1} \mathrm{Cu}$ (Fig. 1C).

\section{Post-metamorphic survival and growth}

Survival and growth of recruits was assessed from Days 5 to 20 because attachment and the initiation of metamorphosis after $24 \mathrm{~h}$ cannot be equated with survival and the completion of metamorphosis into an adult zooid. Census at Day 5 revealed $100 \%$ mortality of all bryozoans in the $500 \mu \mathrm{g} \mathrm{l}^{-1} \mathrm{Cu}$ treatment (Fig. 2). $100 \%$ mortality was also recorded for Schizoporella errata and Tricellaria occidentalis in 50 and $100 \mu \mathrm{g} \mathrm{l}^{-1}$ $\mathrm{Cu}$ treatments (Fig. 2c,d). Overall post-metamorphic survival of recruits was highest in 0 and $10 \mu \mathrm{g} \mathrm{l}^{-1} \mathrm{Cu}$ for all species, with only Bugula neritina and Watersipora subtorquata recruits surviving at 50 and $100 \mu \mathrm{g} \mathrm{l}^{-1} \mathrm{Cu}$ (Fig. 2). Where $100 \%$ mortality was recorded for a particular $\mathrm{Cu}$ concentration at Day 5, this treatment was excluded from the repeated measures analysis as no further potential for a change in survival through time between Days 5 and 20 was possible. Similarly, treatments with insufficient replicates $(\mathrm{n}<4)$ as a result of mortality were also excluded from repeated measures analysis.

There was generally little change in recruit survival between Days 5 and 20 (Fig. 2). There was a significant $\mathrm{Cu}$ treatment by time interaction for Bugula neritina (Table 1) due to the large mortality of recruits in the $50 \mu \mathrm{g} \mathrm{l}^{-1} \mathrm{Cu}$ treatment between Days 5 and 10 (Fig. 2a). Analysis of Watersipora subtorquata survival showed a significant difference between $\mathrm{Cu}$ treatments (Table 1, Fig. $2 b$ ) with planned comparisons showing this difference to exist between 0 and $50 \mathrm{\mu g} \mathrm{l}^{-1} \mathrm{Cu}$ from Days 5 to 20 (Table 1, Fig. 2b). Five percent survival was recorded for $W$. subtorquata recruits in $100 \mu \mathrm{g} \mathrm{l}^{-1} \mathrm{Cu}$ (Fig. 2b), though this was not included in the analysis. There were no significant differences between 0 and $10 \mathrm{\mu g}^{-1} \mathrm{Cu}$ treatments for Schizoporella errata, with time not used as a factor for analysis since there was no
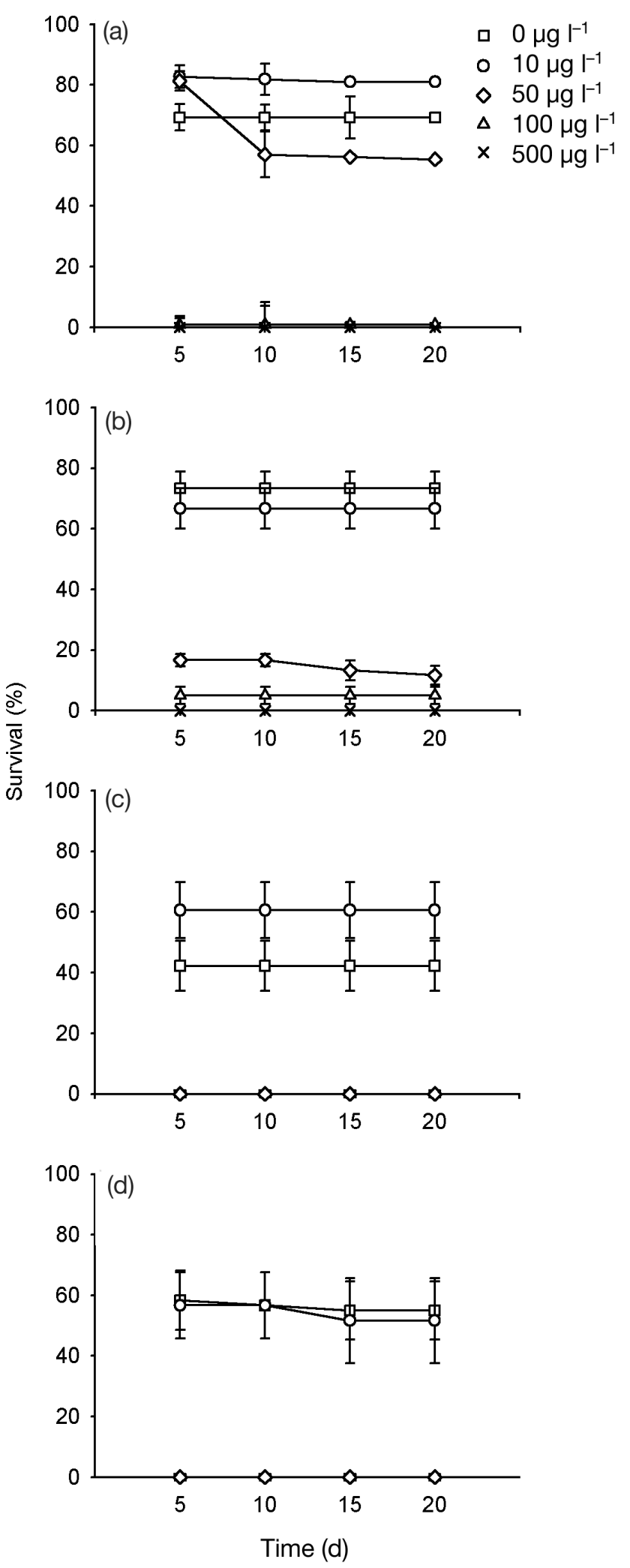

Fig. 2. Effects of $0,10,50,100$ and $500 \mu \mathrm{g} \mathrm{l}^{-1} \mathrm{Cu}$ exposure on the survival of (a) Bugula neritina, (b) Watersipora subtorquata, (c) Schizoporella errata and (d) Tricellaria occidentalis recruits over $20 \mathrm{~d}$. Values represent the mean $( \pm 1 \mathrm{SE})$ 
Table 1. Summary of repeated measures analyses for laboratory toxicity experiments on the survival of bryozoan recruits exposed to copper treatments over $20 \mathrm{~d}$. Degrees of freedom (df), mean square errors (MS) and probability $(p)$ values are presented to enable reconstruction of the full analysis table. $p$-values in bold indicate significant differences at $\alpha=0.050$; absence of variation in survival over time

\begin{tabular}{|c|c|c|c|c|c|}
\hline Factors & Source & $\begin{array}{l}\mathrm{Cu} \text { treatments } \\
\text { analysed }\left(\mu \mathrm{g}^{-1}\right)\end{array}$ & df & $\begin{array}{l}\text { Main test } \\
\text { MS }\end{array}$ & $\mathrm{p}$ \\
\hline \multicolumn{6}{|c|}{ Bugula neritina } \\
\hline Between & $\begin{array}{l}\text { Cu treatment } \\
\text { Error }\end{array}$ & $0,10,50$ & $\begin{array}{c}2 \\
15\end{array}$ & $\begin{array}{l}0.227 \\
0.116\end{array}$ & 0.176 \\
\hline Within & $\begin{array}{l}\text { Time } \\
\text { Time } \times \text { Cu treatment } \\
\text { Error }\end{array}$ & & $\begin{array}{c}3 \\
6 \\
45\end{array}$ & $\begin{array}{l}0.035 \\
0.030 \\
0.003\end{array}$ & $\begin{array}{l}0.003^{\mathrm{a}} \\
\mathbf{0 . 0 0 2}^{\mathrm{a}}\end{array}$ \\
\hline \multicolumn{6}{|c|}{ Watersipora subtorquata } \\
\hline Between & $\begin{array}{l}\text { Cu treatment } \\
\text { Error }\end{array}$ & $0,10,50$ & $\begin{array}{c}2 \\
15\end{array}$ & $\begin{array}{l}2.483 \\
0.064\end{array}$ & 0.000 \\
\hline Within & $\begin{array}{l}\text { Time } \\
\text { Time } \times \text { Cu treatment } \\
\text { Error }\end{array}$ & & $\begin{array}{c}3 \\
6 \\
45\end{array}$ & $\begin{array}{l}0.001 \\
0.001 \\
0.001\end{array}$ & $\begin{array}{l}0.234^{\mathrm{a}} \\
0.237^{\mathrm{a}}\end{array}$ \\
\hline \multicolumn{6}{|c|}{ Schizoporella errata } \\
\hline Between & $\begin{array}{l}\text { Cu treatment } \\
\text { Error }\end{array}$ & 0,10 & $\begin{array}{c}1 \\
10\end{array}$ & $\begin{array}{l}0.101 \\
0.046\end{array}$ & 0.168 \\
\hline Within & $\begin{array}{l}\text { Time } \\
\text { Time } \times \mathrm{Cu} \text { treatment } \\
\text { Error }\end{array}$ & & $\begin{array}{l}- \\
-\end{array}$ & $\begin{array}{l}- \\
-\end{array}$ & $\begin{array}{l}- \\
-\end{array}$ \\
\hline \multicolumn{6}{|c|}{ Tricellaria errata } \\
\hline Between & $\begin{array}{l}\text { Cu treatment } \\
\text { Error }\end{array}$ & 0,10 & $\begin{array}{c}1 \\
10\end{array}$ & $\begin{array}{l}0.005 \\
0.299\end{array}$ & 0.898 \\
\hline Within & $\begin{array}{l}\text { Time } \\
\text { Time } \times \text { Cu treatment } \\
\text { Error }\end{array}$ & & $\begin{array}{c}3 \\
3 \\
30\end{array}$ & $\begin{array}{l}0.006 \\
0.001 \\
0.003\end{array}$ & $\begin{array}{l}0.189^{\mathrm{a}} \\
0.642^{\mathrm{a}}\end{array}$ \\
\hline
\end{tabular}
$p=0.000$ denotes values $<0.0005$. - : no analysis conducted due to complete

concentrations of $50 \mu \mathrm{g} \mathrm{l^{-1 }} \mathrm{Cu}$ reduced growth compared to controls at Days 15 and 20 (Table 2, Fig. 3a,b). Some growth (addition of new zooids) was observed among surviving colonies of both $B$. neritina and $W$. subtorquata at $50 \mu \mathrm{g} \mathrm{l}^{-1} \mathrm{Cu}$ (Fig. 3a,b), however for $B$. neritina the average number of live zooids per colony remained essentially unchanged after $10 \mathrm{~d}$ due to concurrent mortality of older zooids within the colonies (Fig. 3a). There was no growth observed at $100 \mu \mathrm{g} \mathrm{l}^{-1} \mathrm{Cu}$ for either of these species (Fig. 3a,b). Growth for Schizoporella errata was much higher at 0 than $10 \mu \mathrm{g} \mathrm{l}^{-1} \mathrm{Cu}$ by Days 15 and 20 (Table 2, Fig. 3c). The highest growth among all species at both 0 and $10 \mu \mathrm{g}^{-1} \mathrm{Cu}$ was recorded for $T$. occidentalis (Fig. 3d), with a significant $\mathrm{Cu}$ treatment by time interaction occurring (Table 2). Planned comparisons showed this difference to be significant at Day $20\left(F_{1,10}=5.006 ; \mathrm{p}=0.049\right)$.

The nominal and measured $\mathrm{Cu}$ concentrations taken at the commencement of the $20 \mathrm{~d}$ larval toxicity experiments are shown in Table 3.

\section{Laboratory-to-field transfer}

Survival rates in the field were calculated as a proportion of the number of change in survival for either of the treatments for the duration of the experiment (Table 1, Fig. 2c). No significant difference was recorded between 0 and $10 \mu \mathrm{g} \mathrm{l}^{-1}$ $\mathrm{Cu}$ treatments or time for Tricellaria occidentalis (Table 1, Fig. 2d).

Post-metamorphic growth was assessed as the change in the average number of live zooids per colony. As for survival analysis, growth was analysed only for treatments with $<100 \%$ mortality at Day 5, with the exception of Bugula neritina and Watersipora subtorquata at $100 \mathrm{\mu g} \mathrm{l}^{-1} \mathrm{Cu}$ which were omitted from the analyses because survival was recorded in only 1 and 2 replicates respectively. Therefore the $\mathrm{Cu}$ treatments analysed for growth differed among species, with 0, 10 and $50 \mu \mathrm{g} \mathrm{l}^{-1} \mathrm{Cu}$ analysed for B. neritina and W. subtorquata, and 0 and $10 \mu \mathrm{g} \mathrm{l}^{-1} \mathrm{Cu}$ for Schizoporella errata and Tricellaria occidentalis (Table 2).

A significant $\mathrm{Cu}$ treatment by time interaction was observed in post-metamorphic growth for all species (Table 2). The planned comparisons for Bugula neritina and Watersipora subtorquata showed that copper colonies transplanted alive (not the number of initial inoculants). After $26 \mathrm{~d}$ in the field there was some mortality (ranging from 12 to $65 \%$ ) but this was independent of previous $\mathrm{Cu}$ exposure (Fig. 4).

Growth of Bugula neritina colonies in the field were not affected by previous copper treatment, with the average number of bifurcations differing by only $\sim 0.1$ between the 0 and $50 \mu \mathrm{g} \mathrm{l}^{-1} \mathrm{Cu}$ treatments (Table 4 , Fig. 5a). Watersipora subtorquata growth was dramatically reduced by previous exposure to $50 \mu \mathrm{g} \mathrm{l}^{-1} \mathrm{Cu}$ treatments $\left(F_{3,20}=36.467\right.$; Table 4 , Fig. 5b). Surprisingly, growth was recorded for $2 \mathrm{~W}$. subtorquata recruits initially exposed to $100 \mu \mathrm{g} \mathrm{l} \mathrm{l}^{-1} \mathrm{Cu}$ that appeared blackened and dead prior to field deployment (Figs. 5c \& 6); however, lack of sufficient replicates for this treatment prevented it from being used in the analysis. There was no difference in Schizoporella errata and Tricellaria occidentalis growth between 0 and $10 \mu \mathrm{g} \mathrm{l}^{-1} \mathrm{Cu}$, though there was a slight trend in both species for decreased growth with increased copper (Table 4, Fig. 5c,d). 


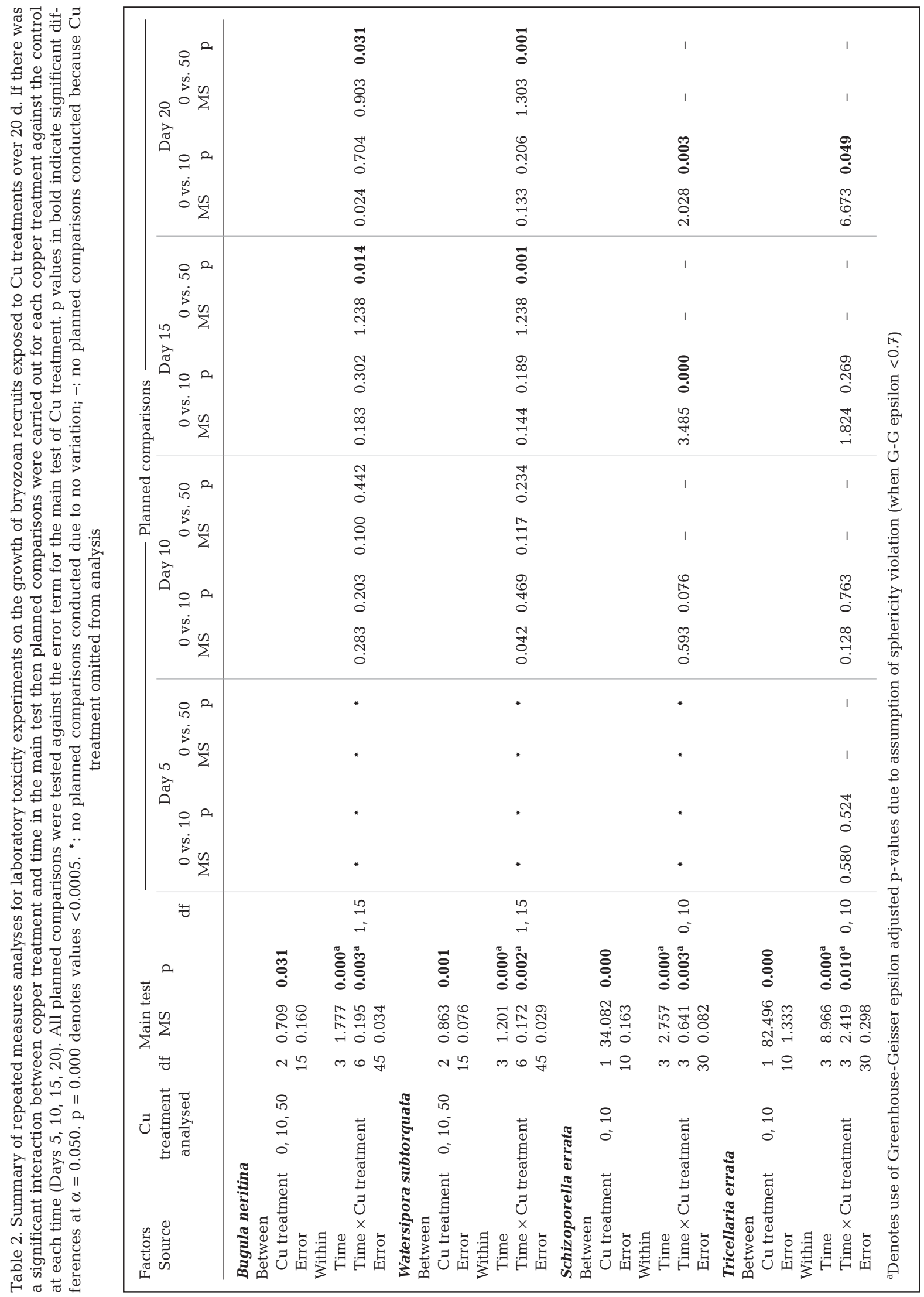



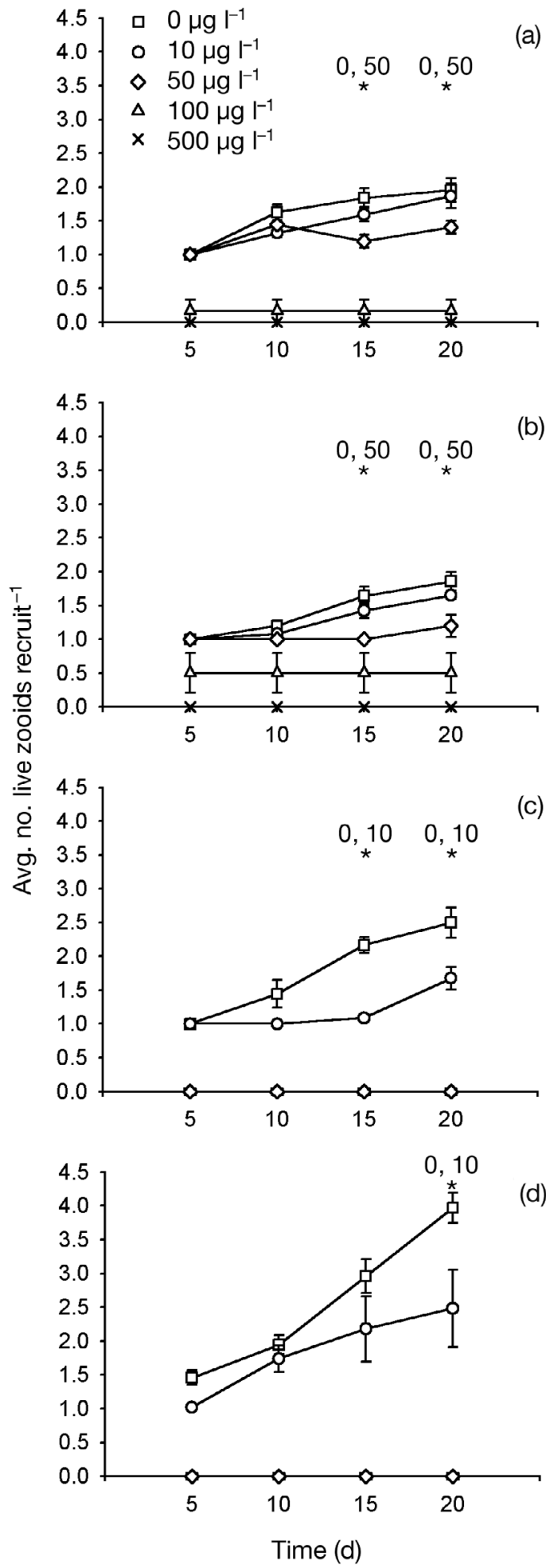

Fig. 3. Effects of $0,10,50,100$ and $500 \mu \mathrm{g} \mathrm{l}^{-1} \mathrm{Cu}$ exposure on the growth of (a) Bugula neritina, (b) Watersipora subtorquata, (c) Schizoporella errata and (d) Tricellaria occidentalis recruits over $20 \mathrm{~d}$. Values represent the mean $( \pm 1 \mathrm{SE})$. *Represent significant differences based on planned comparisons, with numbers shown being the $\mathrm{Cu}$ concentrations that differed
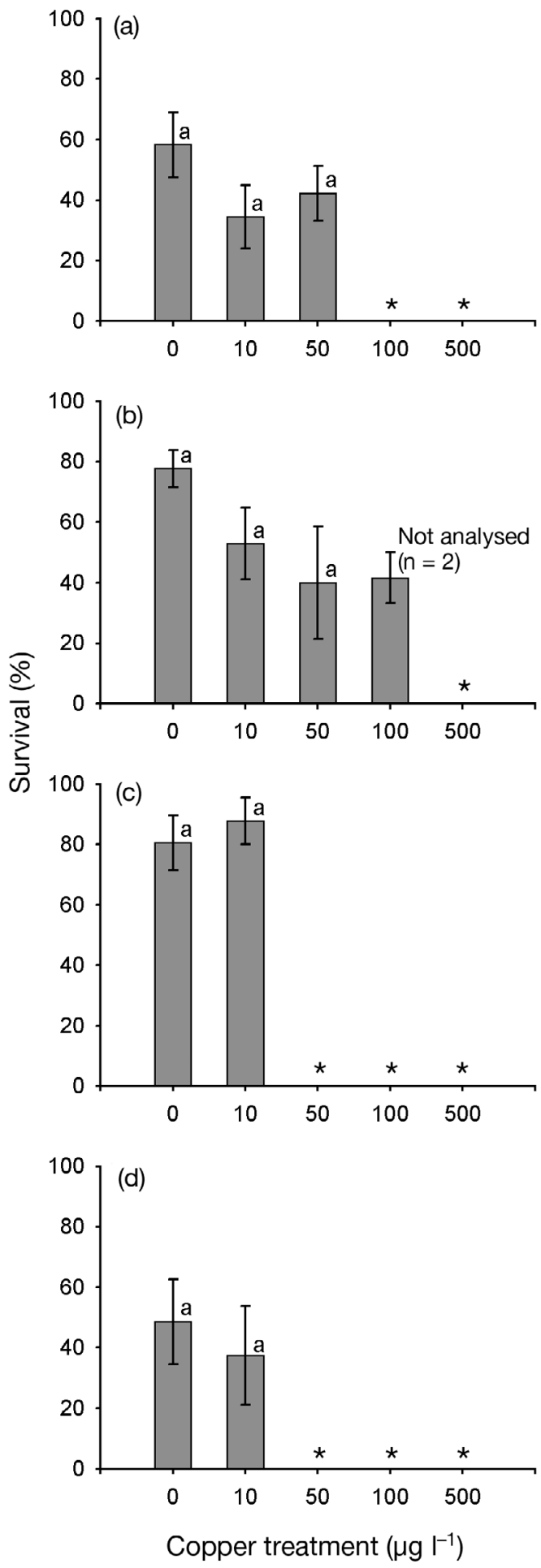

Fig. 4. Survival in the field of (a) Bugula neritina, (b) Watersipora subtorquata, (c) Schizoporella errata and (d) Tricellaria occidentalis recruits following $20 \mathrm{~d}$ exposure to $0,10,50,100$ and $500 \mathrm{\mu g} \mathrm{l}^{-1} \mathrm{Cu}$. Values represent the mean $( \pm 1 \mathrm{SE}) .{ }^{*}$ Represent $\mathrm{Cu}$ treatments that were not transferred to the field due to $0 \%$ survival in laboratory trials. Different letters represent significant differences in Tukey's post-hoc comparisons $(\alpha=0.05)$ 
Table 3. Nominal and measured $\mathrm{Cu}$ concentrations $\left(\mu \mathrm{g} \mathrm{l}^{-1}\right)$ for $\mathrm{Cu}$ treatments used during $20 \mathrm{~d}$ toxicity experiments $( \pm 1 \mathrm{SE}$; $\mathrm{n}=2$ ). Lowest detection limit for analysis was $5 \mu \mathrm{g} \mathrm{\textrm {l } ^ { - 1 }}$

\begin{tabular}{|lc|}
\hline Nominal concentration & Measured concentration \\
\hline 0 & $<5$ \\
10 & $12.2 \pm 3.9$ \\
50 & $47.5 \pm 8.5$ \\
100 & $88.0 \pm 12$ \\
500 & $450.0 \pm 60$ \\
\hline
\end{tabular}

\section{DISCUSSION}

The introduced bryozoans Bugula neritina, Watersipora subtorquata, Schizoporella errata and Tricellaria occidentalis displayed a wide range of $\mathrm{Cu}$ tolerances, and the magnitude of tolerance could not be determined by assessing initial larval attachment. Assessment of the post-metamorphic survival and growth of individuals exposed to $\mathrm{Cu}$ over extended time periods (weeks) followed by a period of field transplantation allowed us to determine tolerance, carry-over effects and recovery ability in a real world ecological context.

Larval attachment success after $24 \mathrm{~h}$ was the first toxicity test end-point we examined, however this proved an unreliable indicator of successful metamorphosis or survival beyond $24 \mathrm{~h}$. Previous studies have suggested that $\mathrm{Cu}$ may induce and accelerate the attachment of Watersipora sp. and Bugula neritina larvae (Wisely 1962a, b, Ng \& Keough 2003). In contrast, our study showed reduced attachment success in Watersipora subtorquata up until $500 \mu \mathrm{g} \mathrm{l^{-1 }} \mathrm{Cu}$. Moreover, there was no inducement of attachment by $\mathrm{Cu}$ in Bugula neritina and Tricellaria occidentalis, and only a slight increase in Schizoporella errata attachment at $50 \mu \mathrm{g} \mathrm{l^{-1 }} \mathrm{Cu}$. In contrast to initial attachment success, survival at Day 5 was a substantially better indicator of $\mathrm{Cu}$ tolerance. Larvae that were able to attach, metamorphose and survive to Day 5 invariably remained alive for the $20 \mathrm{~d}$ duration of the laboratory experiment.

Post-metamorphic survival and growth observations indicated a wide range of $\mathrm{Cu}$ tolerance among the introduced bryozoans. While Schizoporella errata and Tricellaria occidentalis suffered increased mortality and reduced growth following only small increases in $\mathrm{Cu}\left(10 \mu \mathrm{g} \mathrm{l}^{-1}\right)$, Bugula neritina and Watersipora subtorquata were able to survive in all $\mathrm{Cu}$ treatments up to and including $100 \mu \mathrm{g} \mathrm{I}^{-1}$. One source of $\mathrm{Cu}$ in ports and harbours is antifouling paints. In situ studies on the release of $\mathrm{Cu}$ from freshly painted antifouling coatings show that release rates, while initially high at 25 to $65 \mu \mathrm{g} \mathrm{Cu} \mathrm{cm}{ }^{-2} \mathrm{~d}^{-1}$, quickly decreased to much lower levels of 9 to $25 \mu \mathrm{g} \mathrm{Cu} \mathrm{cm}{ }^{-2} \mathrm{~d}^{-1}$ after only $30 \mathrm{~d}$ of submersion (Valkirs et al. 2003). Since results of this study indicate that larvae of Bugula neritina and Watersipora subtorquata are able to successfully settle, survive, and grow in $\mathrm{Cu}$ concentration well within even this initial range, it is possible that larvae of these species would be able to recruit onto hulls of vessels with freshly painted antifouling coatings. Indeed, field experiments have shown that $W$. subtorquata and $B$. neritina are able to grow directly upon or within close proximity to surfaces coated with copper-based antifouling paints (Johnston \& Webb 2000, Floerl et al. 2004). Provided these recruits were then able to survive the initially high $\mathrm{Cu}$ concentrations for the first 20 to $30 \mathrm{~d}$ postattachment (as is also demonstrated in this study) then they would have a very good chance of establishing a colony and growing through to reproductive maturity. Combining this scenario with the fact that modern ves-

Table 4. ANOVA for the survival and growth of bryozoan recruits transferred to the field. Recruits had previously been exposed to 0,10 and $50 \mathrm{\mu g} \mathrm{l}^{-1} \mathrm{Cu}$ in the lab. Degrees of freedom (df), mean square errors (MS) and probability (p) values are presented to enable reconstruction of the full analysis table. $p$-values in bold indicate significant differences at $\alpha=0.050 ; p=0.000$ denotes values $<0.0005$

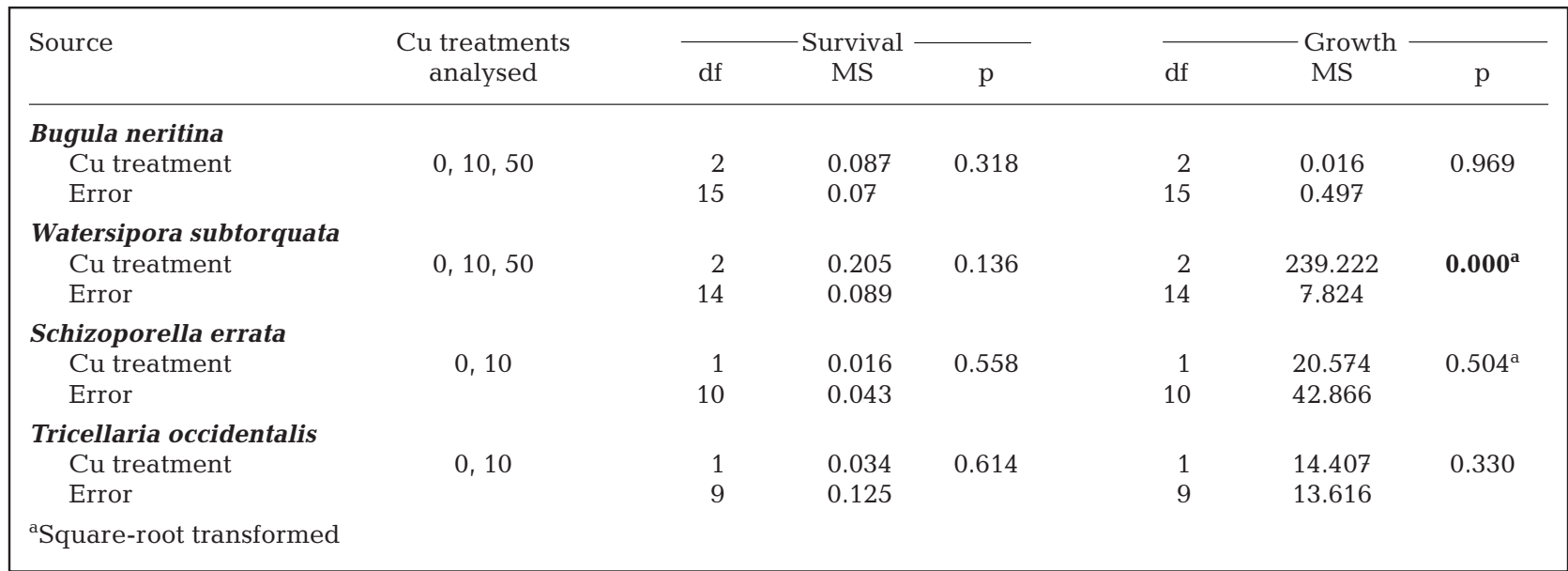



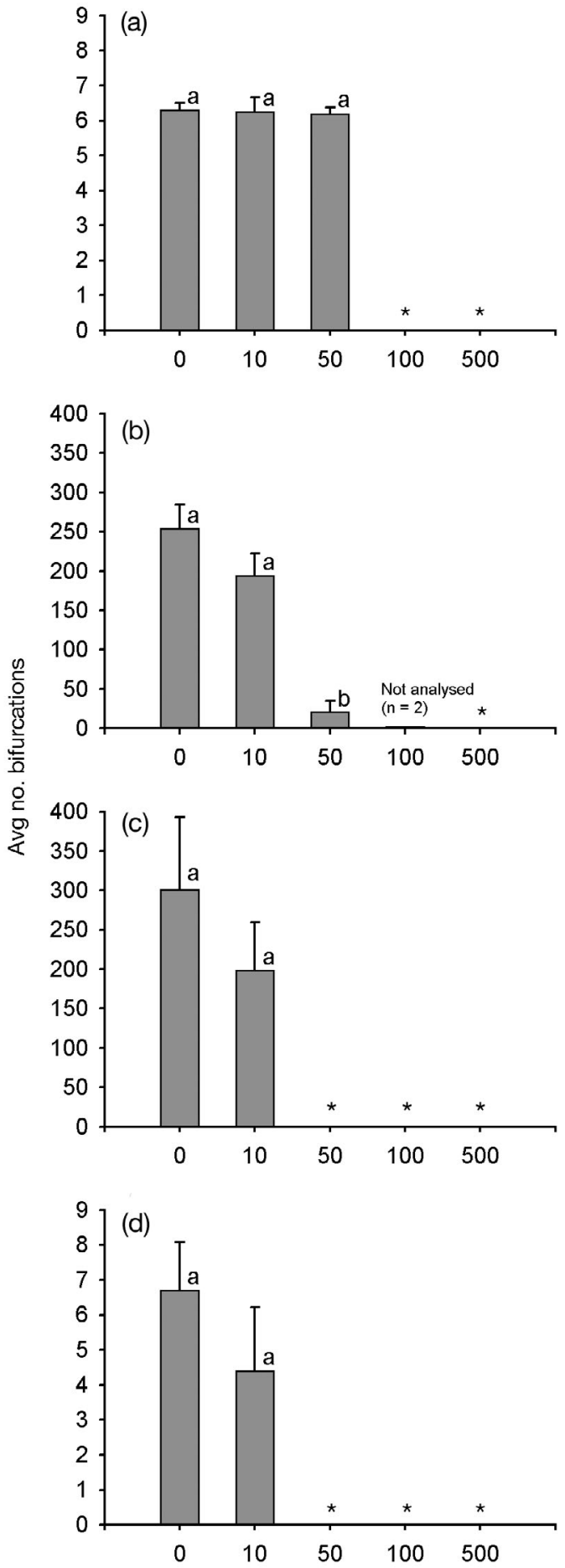

Copper treatment $\left(\mu \mathrm{g} \mathrm{l}^{-1}\right)$

Fig. 5. Growth in the field of (a) Bugula neritina, (b) Watersipora subtorquata, (c) Schizoporella errata and (d) Tricellaria occidentalis recruits following $20 \mathrm{~d}$ exposure to $0,10,50,100$ and $500 \mathrm{\mu g} \mathrm{l}^{-1} \mathrm{Cu}$. Values represent the mean $( \pm 1 \mathrm{SE}) .{ }^{*} \mathrm{Rep}-$ resent $\mathrm{Cu}$ treatments that were not transferred to the field due to $0 \%$ survival in laboratory trials. Different letters represent significant differences in Tukey's post-hoc comparisons $(\alpha=0.05)$
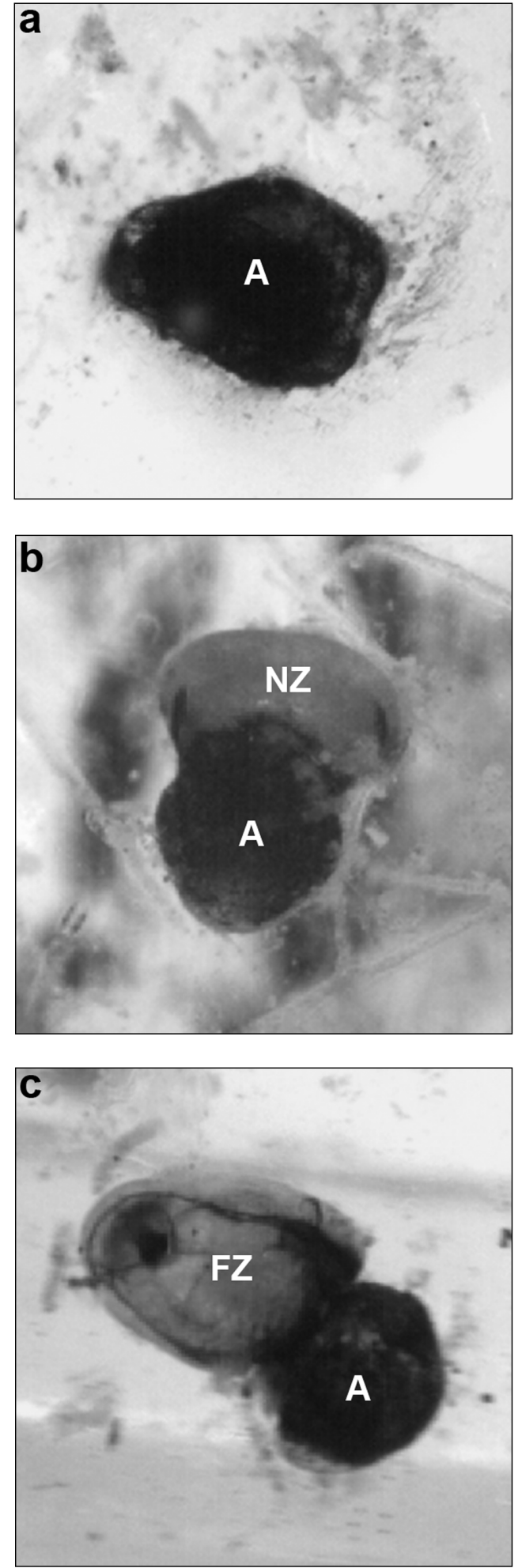

Fig. 6. Watersipora subtorquata recruits settled and grown in $100 \mathrm{~g} \mathrm{l}^{-1} \mathrm{Cu}$ in the laboratory for $20 \mathrm{~d}$ then transplanted into the field for $28 \mathrm{~d}$, showing (a) blackened and dead ancestrula (A), (b) formation of a new zooid (NZ) from the blackened ancestrula (A), and (C) fully functional zooid (FZ) budded from the blackened ancestrula (A) 
sels can travel to almost any port or harbour in the world within several days or weeks, there exists the enormous potential for nonindigenous species introductions from vessels that are mistakenly considered to be free of and protected from hull-fouling organisms.

Watersipora subtorquata and Bugula neritina are cosmopolitan fouling species occurring abundantly in ports and harbours around the globe (Gordon \& Mawatari 1992, Hayes et al. 2004). Given that these species may be further exposed to toxicants, such as copper, within the ports and harbours which they inhabit (Paulson et al. 1989, Weis \& Weis 1992, 1996, Apte \& Day 1998, Hall et al. 1998, Pitt 2002) their tolerance to toxicants may also provide them with the competitive advantage needed to outcompete other organisms within these communities. While pollution may play an important role in mediating the introduction and spread of nonindigenous species such as Watersipora subtorquata and Bugula neritina, there are undoubtedly other factors that allow toxicantintolerant nonindigenous marine species (such as Schizoporella errata and Tricellaria occidentalis) to become successful invasive species. Examples of possible factors include ballast water discharge (Carlton 1989) or physical disturbance (Clark \& Johnston 2005). In the context of hull-fouling bryozoan species, the results of this study suggest that $B$. neritina and $W$. subtorquata would be the most common introduced species found in harbours and estuaries.

Bryozoans demonstrated a strong ability to recover from extended periods of $\mathrm{Cu}$ exposure. After $26 \mathrm{~d}$ in the field, there was no difference in the survival or growth of Bugula neritina irrespective of previous $\mathrm{Cu}$ exposure. Moreover, regardless of $\mathrm{Cu}$ exposure, the average growth rates were similar to those recorded for similarly aged colonies observed in previous studies (Keough 1989).

Following transplantation to the field, recruits of $\mathrm{Wa}$ tersipora subtorquata showed no difference in survival across $\mathrm{Cu}$ treatments, however colonies exposed to $50 \mu \mathrm{g}$ $\mathrm{l}^{-1} \mathrm{Cu}$ had $92 \%$ decreased growth after $46 \mathrm{~d}$. Smaller effects on growth have been observed following short term (6 h) exposures of W. subtorquata larvae to $100 \mu \mathrm{g} \mathrm{l}^{-1} \mathrm{Cu}$ (Ng \& Keough 2003). With approximately 200 to 280 zooids per colony after $7 \mathrm{wk}$, the growth rates of our control colonies were comparable to those of a similar age from other studies ( $\mathrm{Ng} \&$ Keough 2003) suggesting no adverse effects of prolonged laboratory rearing. Given that the survival and growth of just 1 or 2 individuals from a population may be sufficient for a successful invasion to occur, it is worth noting that several recruits of $W$. subtorquata did display remarkable recovery ability in the field following exposure to $100 \mu \mathrm{g}^{-1} \mathrm{Cu}$ (Fig. 6). All recruits exposed to $100 \mu \mathrm{g} \mathrm{l}^{-1} \mathrm{Cu}$ appeared blackened and dead and displayed no feeding activity for the $20 \mathrm{~d}$ duration of the laboratory study. After transplantation to the field however, budding and growth was evident from several of the still blackened ancestrula. This remarkable ability of new recruits to 'shut-down' under extended exposure to a toxicant, followed by recovery and growth, gives $W$. subtorquata a potentially enormous competitive advantage over other colonising species; whereby it is able to recruit to highly disturbed areas, lie dormant, and recover once conditions improve.

The ability of these bryozoan colonies to recover following extended periods of $\mathrm{Cu}$ exposure stresses the importance for field observations as a component of ecotoxicology studies. This study clearly demonstrates that while larvae and recruits may exhibit adverse effects to toxicants during periods of extended exposure, once this exposure period has passed there may be little or no persistent carry-over effects. This also has important implications for the management and control of invasive marine hull-fouling species. It is not sufficient to simply rely upon relatively short experiments $(72$ or $96 \mathrm{~h}$ ) examining larval attachment or metamorphosis to draw conclusions regarding the effectiveness of antifouling strategies. Field transplant observations must follow in order to properly assess the recovery abilities and/or carry-over effects of organisms following periodic toxicant exposure. Such field transplants would also address concerns regarding the real world ecological significance of many ecotoxicology studies (Chapman 2002).

Acknowledgements. We are grateful to G. Clark and K. Lee for their assistance with field and laboratory work. We thank K. Gotham, G. Wicks and all the staff of the Caltex Refinery for providing access to Kurnell Pier. We are indebted to K. Wright, the Johnston and Poore labs and the 4 anonymous reviewers for their helpful and insightful comments on the original manuscript and G. Batley and S. Simpson for advice regarding chemistry and water analysis. R.F.P. was supported throughout this study by and Australian Government Postgraduate Award (APA). This study was partially funded by an Australian Research Council (ARC) Discovery Grant awarded to E.L.J.

\section{LITERATURE CITED}

Abel P (1989) The toxicity of pollutants to aquatic organisms. In: Horwood E (ed) Water pollution biology. Chichester, p 100-139

Apte SC, Day GM (1998) Dissolved metal concentrations in the Torres Strait and Gulf of Papua. Mar Pollut Bull 36: 298-304

ASTM (1999) Annual book of ASTM standards, Vol 11.05. American Society for Testing and Materials, West Conshocken, PA

Batley G, Apte SC, Stauber JL (2004) Speciation and bioavailability of trace metals in water: progress since 1982. Aust J Chem 57:903-919

Brusca RC, Brusca GJ (1990) The Lophophorate Phyla: Phoronids, Ectoprocts and Branchiopods. In: Brusca RC, Brusca GJ (eds) Invertebrates. Sinauer Associates, Sunderland, MA, p 788 
Calabrese A, Collier R, Nelson DA, MacInnes J (1973) The toxicity of heavy metals to embryos of the American oyster Crassostrea virginica. Mar Biol 18:162-166

Callow P (1994) Handbook of ecotoxicology, Vol 2. Blackwell Scientific Publications, Oxford

Campbell PGC (1995) Interactions between trace metals and aquatic organisms: a critique of the Free-ion Activity Model. In: Tessier A, Turner DR (eds) Metal Speciation and Bioavailability in Aquatic Systems, Vol 3. Wiley \& Sons, Chichester, p 45-102

Carlton JT (1989) Man's role in changing the face of the ocean: biological invasions and implications for conservation of near-shore environments. Conserv Biol 3: 265-273

Carlton JT, Geller JB (1993) Ecological roulette: The global transport of nonindigenous marine organisms. Science 261:78-82

Chapman PM (2002) Integrating toxicology and ecology: putting the 'eco' into ecotoxicology. Mar Pollut Bull 44: $7-15$

Clark G, Johnston EL (2005) Manipulating larval supply in the field: a controlled study of marine invasibility. Mar Ecol Prog Ser 298:9-19

Cohen AN, Carlton JT (1998) Accelerating invasion rate in a highly invaded estuary. Science 279:555-557

Connor PM (1972) Acute toxicity of heavy metals to some marine larvae. Mar Pollut Bull 3:190-192

Floerl O, Pool TK, Inglis GJ (2004) Positive interactions between nonindigenous species facilitate transport by human vectors. Ecol Appl 14:1724-1736

Gordon DP, Mawatari SF (1992) Atlas of marine-fouling Bryozoa of New Zealand ports and harbours. Miscellaneous Publications, New Zealand Oceanographic Institute 107: $1-52$

Hall LW Jr, Scott MC, Killen WD (1998) Ecological risk assessment of copper and cadmium in surface waters of Chesapeake Bay watershed. Environ Toxicol Chem 17: 1172-1189

Hayes K, Sliwa C, Migus S, McEnnulty F, Dunstan P (2004) National priority pests - Part II: Ranking of Australian marine pests, CSIRO Marine Research for the Australian Department of Environment and Heritage, Parkes

Hewitt CL, Campbell ML, Thresher RE, Martin RB and 15 others (2004) Introduced and cryptogenic species in Port Phillip Bay, Victoria, Australia. Mar Biol 144:183-202

Holloway MG, Keough MJ (2002) An introduced polychaete affects recruitment and larval abundance of sessile invertebrates. Ecol Appl 12:1803-1823

I.M.O. (2001) International Conference on the Control of Harmful Anti-fouling Systems for Ships, Adoption of the Final Act of the Conference and Any Instruments, Recommendations and Resolutions Resulting From the Work of the Conference. International Maritime Organisation, IMO Headquarters, London, p 15

Johnston EL, Webb J (2000) Novel techniques for field assessment of copper toxicity of fouling assemblages. Biofouling 15:165-173

Johnston EL, Keough MJ, Qian PY (2002) Maintenance of species dominance through pulse disturbances to a sessile marine invertebrate assemblage in Port Shelter, Hong Kong. Mar Ecol Prog Ser 226:103-114

Keough MJ (1989) Variation in growth rate and reproduction of the bryozoan Bugula neritina. Biol Bull 177:277-286

Keough MJ, Chernoff H (1987) Dispersal and population variation in the bryozoan Bugula neritina. Ecology 68:199-210

Luoma SN, Phillips DJH (1988) Distribution, variability and impacts of trace elements in San Francisco Bay. Mar Pollut Bull 19:413-425

McKim JM (1977) Evaluation of tests with early life stages of fish for predicting long-term toxicity. J Fish Res Board Can 34:459-472

Minchin D, Gollasch S (2003) Fouling and ships' hulls: How changing circumstances and spawning events may result in the spread of exotic species. Biofouling 19:111-122

Ng TY-T, Keough MJ (2003) Delayed effects of larval exposure to $\mathrm{Cu}$ in the bryozoan Watersipora subtorquata. Mar Ecol Prog Ser 257:77-85

Paulson AJ, Curl HCJ, Feely RA (1989) Estimates of trace metal inputs from non-point sources discharged into estuaries. Mar Pollut Bull 20:549-555

Pitt RE (2002) Receiving water impacts associated with urban wet weather flows. In: Hoffman DJ, Rattner BA, Burton GAJ, Cairns JJ (eds) Handbook of Ecotoxicology. Lewis Publishers, Boca Raton, FL, p 575-613

Pollard DA, Pethebridge RL (2002) Report on Port of Botany Bay Introduced Marine Pest Species Survey. Report No. 40, New South Wales Fisheries Office of Conservation, Cronulla

Preston BL, Shackelford J (2002) Multiple stressor effects on benthic biodiversity of Chesapeake Bay: Implications for ecological risk assessment. Ecotoxicol 11:85-99

Quinn GP, Keough MJ (2002) Experimental design and data analysis for biologists. Cambridge University Press, Cambridge

Rygg B (1985a) Effect of sediment copper on benthic fauna. Mar Ecol Prog Ser 25:83-89

Rygg B (1985b) Distribution of species along pollutioninduced diversity gradients in benthic communities in Norwegian fjords. Mar Pollut Bull 16:469-474

Scanes P (1996) 'Oyster Watch': Monitoring trace metal and organochlorine concentrations in Sydney's coastal waters. Mar Pollut Bull 33:226-238

Schiff K, Diehl D, Valkirs AO (2004) Copper emissions from antifouling paint on recreational vessels. Mar Pollut Bull 48:371-377

Stauber JL, Benning RJ, Hales LT, Eriksen R, Nowak B (2000) Copper bioavailability and amelioration of toxicity in Macquarie Harbour, Tasmania, Australia. Mar Freshw Res 51: $1-10$

Valkirs AO, Seligman PF, Haslbeck E, Caso JS (2003) Measurement of copper release rates from antifouling paint under laboratory and in situ conditions: implications for loading estimation to marine water bodies. Mar Pollut Bull 46:763-779

Weis JS, Weis P (1992) Construction materials in estuaries: reduction in the epibiotic community on chromated copper arsenate (CCA) treated wood. Mar Ecol Prog Ser 83: $45-53$

Weis JS, Weis P (1996) Reduction in toxicity of chromated copper arsenate (CCA)- treated wood as assessed by community study. Mar Environ Res 41:15-25

Wisely B (1958) The settling and some experimental reactions of a bryozoan larva, Watersipora cucullata (Busk). Aust J Mar Fresh Res 9:362-371

Wisely B (1962a) Effect of an anti-fouling paint on a bryozoan larva. Nature 193:543-544

Wisely B (1962b) Effects of antifouling paints on settling larvae of the bryozoan Bugula neritina L. Aust J Mar Fresh Res 14:44-59

Xie ZC, Wong NC, Qian PY, Qiu JW (2005) Responses of polychaete Hydroides elegans life stages to copper stress. Mar Ecol Prog Ser 285:89-96 